\title{
Biomaterials heterogeneous displacement, strain and swelling under hydric sorption/desorption: 2D image correlation on spruce wood
}

\author{
D. Kosiachevskyi ${ }^{1,2} *$, C. El Hachem ${ }^{1}$, K. Abahri ${ }^{1}$, R. Bennacer ${ }^{1} *$, M. Chaouche ${ }^{1}$ \\ ${ }^{1}$ Université Paris-Saclay, ENS Paris-Saclay, CNRS, LMT - Laboratoire de Mécanique et \\ Technologie, 91190, Gif-sur-Yvette, France \\ ${ }^{2}$ Centre d'Innovation ParexGroup, 38070 St Quentin Fallavier, France
}

\begin{abstract}
Spruce wood, as all biosourced materials, is very sensitive to relative humidity changes, which can cause dimensional variations. In some cases, it leads to eccentricity, degradation and deterioration of the wooden structures. The 3D methods of evaluation of the spruce wood hydric behavior needs important financial resources and investigation. That's why, the main objective of this study is to develop the technics of $2 \mathrm{D}$ digital image correlation to estimate the local displacements and strains values under hydric solicitations and to follow the hysteresis phenomenon, anisotropy and swelling coefficient. In this context, cycles of sorption desorption for relative humidity that vary from 0 to $100 \%$ were applied. Results represent swelling coefficients for early- and latewood as a function of wood directions. A particular attention was devoted to the uncertainty of the 2D digital image correlation technics for both earlywood and latewood. This study provides the literature and future research with promising results especially concerning the evolution of the microscopic morphology of biosourced materials when exposed to relative humidity variations, which can significantly affect their macroscopic behavior.
\end{abstract}

Key words: Morphological characterization, Experimental investigation, Relative humidity, Hysteresis, Spruce wood, Early and latewood

\section{Introduction}

In recent years, questions of energy efficiency and implementation of the energy saving policies have gained particular importance all around the world. Among these preoccupations, the ecological aspect should be certainly considered as well. The 2015 Paris Climate Conference and others underlined several resolutions to reduce the pace of global warming. To achieve this goal, all countries must reduce the amount of greenhouse gas emissions, the main cause being the production of oil and gas the primary sources of energy. With regard to building sector in France, $45 \%$ consumed energy and 29\% of CO2 emitted are due to the residential and commercial buildings' functioning [1].

The need to reduce the amount of greenhouse gas emissions during the production of building materials leads to the use of biosourced materials (wood, hemp concrete, straw, etc.) given their low environmental impact. These materials are used for all types of structures: frame structures, ceilings, isolation and others. Today, the implementation of biosourced building

\footnotetext{
*Corresponding author; e-mail: rachid.bennacer@ens-paris-saclay.fr kosiachevskyi.dima@gmail.com
} 
materials is hampered by the lack of database concerning their intrinsic properties and their thermo-hygro-mechanical behavior that varies through time. In fact, because of wood's heterogeneous and hygroscopic microstructure, it represents considerable dimensional variations under hygrothermal solicitations, which in some cases lead to its degradation and deterioration [2].

Wood, a secondary tissue resulting from the functioning of the peripheral cambium, is considered as a particular biosourced material. Trees, and their derivative products, have been used by societies around the world for thousands of years. However, like any natural material, it is heterogeneous. This heterogeneity is observed in all scales. Longitudinal tracheids are the main constituents of wood, especially in conifers. The lamellar structure and the variation in the chemical composition of the tracheid wall give them specific properties. The secondary cell wall is the most important fiber part, in mechanical and physical terms. Wood fibers are similar to a composite material where lignin represents the matrix; cellulose is the reinforcement, while hemicelluloses play the role of inter-facial agent. The size of the wood cells is from 30 to 40 $\mu \mathrm{m}$, the cell walls are 5 to $10 \mu \mathrm{m}$, depending on the type of wood: earlywood or latewood [3].

Concerning the water properties, the wood stabilizes at equilibrium humidity, called hygroscopic balance, depending on the temperature and, especially, the humidity of the ambient air. Under the temperate climate (actual for most of continental European countries) during the driest period, the atmospheric conditions are of the order of $20^{\circ} \mathrm{C}$ and $70 \%$ relative humidity of the air $(\mathrm{RH})$, which corresponds to a hygroscopic balance of the wood about $13 \%$. During the wettest period, atmospheric conditions are of the order of 0 to $5^{\circ} \mathrm{C}$ and $85 \% \mathrm{RH}$, which corresponds to a hygroscopic balance of wood of about 19\% [4]. As a result, a wooden structure located outside (windows, shutters, cladding) will get its water content about $13 \%$ in summer and $19 \%$ in winter. In order to minimize wood variations its water content must be in the middle of the variation range from 15 to $16 \%$.

Similarly, a wood located inside a heated house will vary in humidity depending on the season. In summer, the conditions of temperature and relative humidity of the air are close to the external conditions: the hygroscopic balance of the wood is of the order of 12 to $13 \%$. In winter, when the temperature is $20^{\circ} \mathrm{C}$ and the relative humidity of the air is close to $30 \%$, the equilibrium humidity is around $7 \%$. This values of water content is the highest one in comparison with ordinary building materials [5].

This hygroscopic character of the wood causes dimensional variations: swelling and shrinkage. The fiber saturation point (FSP) takes place in case of relative humidity of the air of $100 \%$ and at $30 \%$ of water content for the most of wood species. Up to this limit, the cell walls of the wood swell. Beyond, if it is confronted with a driving rain, the material can continue to store the water without dimensional growth. These variations are more or less important depending on the species of wood. Spruce, larch or Scots pine have medium dimensional stability, while that of maritime pine, oak and black locust have low ones [6].

Dimensional variations are often represented as a function of the water content. Determination of water content in the hygroscopic range is usually done by sorption/desorption isotherms. Wood is a hygroscopic material with a pronounced absorption of water vapor in the hygroscopic region. Water vapor sorption in the cell wall is commonly explained as a film in which the water molecules bind in layers at active sorption sites, mainly to polar amino acids on amorphous cellulose and hemicellulose surfaces [7]. Many different theories can be found in the literature that describe water sorption, for example Brunauer [8], Hailwood and Horobin [9] and Peirce [10] that can be applied to wood [11]. All these methods describe sorption in a similar way with some of the moisture associated with cellulose molecules (monolayer formation, hydration, bound water) and the other part is less intimately associated (multilayer formation, dissolved water, liquid). This hypothesis of water sorption mechanism in wood has become an accepted concept [11]. 
The most used hypothesis explains the deformations of the wood by its constitution. Alive spruce wood, like all organic matter, contains a lot of water - more than $40 \%$ of its mass [12]. We differentiate three "water" outlets: the free water, located between the fibers of the wood (in the vessels), water of constitution which constitutes the molecules of the wood, and finally the bound water. This last type of water is contained in the wood fibers and in the cell walls. Until the time when the free water has not evaporated, there is no shrinkage. As soon as the bound water begins to evaporate, the sample is shrinking. The swelling process is the same but in the opposite direction except the effect of hysteresis.

Recently, El Hachem et al. [13] conducted the 3D quantification of the bound and free water of the spruce wood fibers and their interactions. Results showed that with the humidification at the range between dry state and FSP, the bound water quantity increase. After reaching the FSP, as the cell walls are saturated in bound water, further humidification of the spruce wood cause the increase of the free water.

The wood, like all biosourced materials, should be characterized by taking into account the multi-scale factor. It can be seen that the microscopic origin of water behavior is at the level of the cell wall. If we decrease the scale, we can see that the spruce wood tissue is composed of almost equal amount of rigid microfibrils of cellulose and a soft polymer matrix. The hydrophobic crystalline cellulose is surrounded by hydrophilic amorphous cellulose immersed in a hydrophilic amorphous matrix of hemicelluloses bound by lignin.

The sorption of water molecules between hydrophilic molecules removes constituents, resulting in swelling and reduced stiffness of the matrix. The thin inner and outer cell wall layers act as corsets due to the wrapping of the cellulose fibers around the cell. In the central and the thickest cell wall layer, the cellulose microfibrils are almost parallel to the longitudinal axis of the cells. During moisture sorption the general direction of microfibrils result in noticeable swelling in the transverse direction [11]. The deformations of the cell are almost zero in the longitudinal direction (L) $[14,15]$. Although the swelling comes from the scale of the cell wall, its anisotropic nature is found mainly in the cellular architecture.

On a mesoscopic scale, the wood consists mainly of longitudinal tracheid cells and radially oriented radiating cells. Through the growth ring, thin-walled earlywood cells with large internal cavities, called lumens, gradually change into thick-walled hardwood cells with small lumens. Variation of the cell structure through the growth ring is responsible for the anisotropy of swelling and stiffness [16,17]. In addition, the results on the isotropic swelling of the isolated latewood and the anisotropic swelling of the isolated earlywood in the transverse plane indicate the possibility of an early/latewood interaction $[18,19]$.

In order to quantify the swelling, some authors proposed the hypothesis that the volume deformation is equal to the absorbed water volume [14]. This idea doesn't take into account the wood cell (lumens) volume changes due to the humidity content variations. These authors also suggested a formulation for the global swelling coefficient in function of the FSP and the density of the wood. This expression remains rather general as it does not take into account the relative humidities variations. Other authors measured the lumens volume change of earlywood and latewood observing in microtomography the Swedish pine [20]. The results showed that the volume of the earlywood cells decrease from 3 to 3.8\%. On the contrary, the latewood cells volume increased from 2.2 to $4.2 \%$. These two factors compensate each other, and finally [17] estimated that the global decrease of the lumen volumes is about $1-2.5 \%$ of total volume. This estimation is also approximatively and it was not identified for each water content or hydric state of the material.

Rafsanjani et al. [21] investigated the hygro-mechanical behavior using the two-scale model based on a computational homogenization to evaluate the radial and tangential swelling. The anisotropy of the behavior was shown with difference between earlywood and latewood in 
function of the direction. The earlywood represents lower swelling coefficient in the radial direction, at the same time latewood has the swelling ration about 1.0.

Most of investigations on the spruce wood, as a construction material, are interested moreover in characterization of mechanical, thermal or hydric properties and in most cases dimensional variations (swelling and shrinkage) due to hygric solicitations are not taken in account. Moreover, most scientific works investigate the spruce wood on the macroscopic scale but not the microscopic behavior or its heterogeneity. Nevertheless, the dimensional variations in different prediction models induce a very important calculation error and an ignorance of the behavior of this very hygroscopic material. Due to this factor, it is important to describe physical processes of the hygric behavior at the microscopic level in order to predict the macroscopic behavior. In a recent work, we proposed the 3D tomography analysis of the hygromechanical behavior of spruce wood [19], but the price of this method makes it not affordable for each type of application. Indeed, it was experimentally difficult to estimate the local displacement and strain for each relative humidity level from the sorption to the desorption including the hysteresis phenomenon. That's why, the main objective of this study is to develop the simple and reliable technics of $2 \mathrm{D}$ digital image correlation to evaluate the local displacements and strains values under hydric solicitations. The originality is to follow the deformations with regard the hysteresis phenomenon (cycles of sorption - desorption for relative humidity that vary from 0 to $100 \%$ ) for both earlywood and latewood types. Results are represented as swelling coefficients for different types of wood. A particular attention was devoted to the uncertainty of the 2D digital image correlation technics and to the orientation of the spruce wood when representing the strain fields depending of directions.

\section{Material and methods}

In order to analyze microscopic spruce wood comportment and to characterize the dimensional variations when subjected to hygric solicitations, we should start by selecting optimal and representative elementary volume (REV). Basing on the size of cells mentioned before, samples of two sizes have been selected (Table 1), that are representative for spruce wood case (size measured as the average of 6 values with the calipers "Facom 1320" with a precision of $0.01 \mathrm{~mm}$ ). Before the test, samples were dried in a oven until constant mass according to ISO 12571.

Table 1. Spruce wood samples size used during the test

\begin{tabular}{|c|c|c|c|}
\hline $\begin{array}{c}\text { Sample } \\
\text { number }\end{array}$ & Length $(\mathrm{mm})$ & Wight $(\mathrm{mm})$ & $\begin{array}{c}\text { Thickness } \\
(\mathrm{mm})\end{array}$ \\
\hline Sample 1 & $22.39 \pm 0.05$ & $19.81 \pm 0.03$ & $9.5 \pm 0.23$ \\
\hline Sample 2 & $22.24 \pm 0.04$ & $20.15 \pm 0.06$ & $8.74 \pm 0.03$ \\
\hline
\end{tabular}

Concerning the experimental protocol, it consists in taking successive images of a specimen at a reference state and then at various deformed states that are exposed to different controlled relative humidities. To guarantee a constant relative humidity, tanks with specific saturated salt solutions were set up within the desiccators. Each type of saturated salt solution corresponds to a known relative humidity according to its physicochemical properties [22]. In this study, we used sodium chloride $(75 \%)$, potassium chloride $(84 \%)$ and potassium nitrate (93\%). The experimentation was performed in a room at controlled temperature of $25^{\circ} \mathrm{C}$. Concerning the dry state, silica gel was used. To complete the hysteresis curve (from $93 \%$ to $100 \%$ ) and obtain a saturated state of the material, the sample was drowned in water for 24 hours. The thermal effects are negligible because the room temperature is maintained stable. 
The duration of the tests made using salt solutions is more than five days for each relative humidity state, which is long enough in order to guarantee the mass equilibrium within the material of small dimensions. The experimental protocol schematically is represented in the figure 1 including the sample preparation and the measuring protocol.

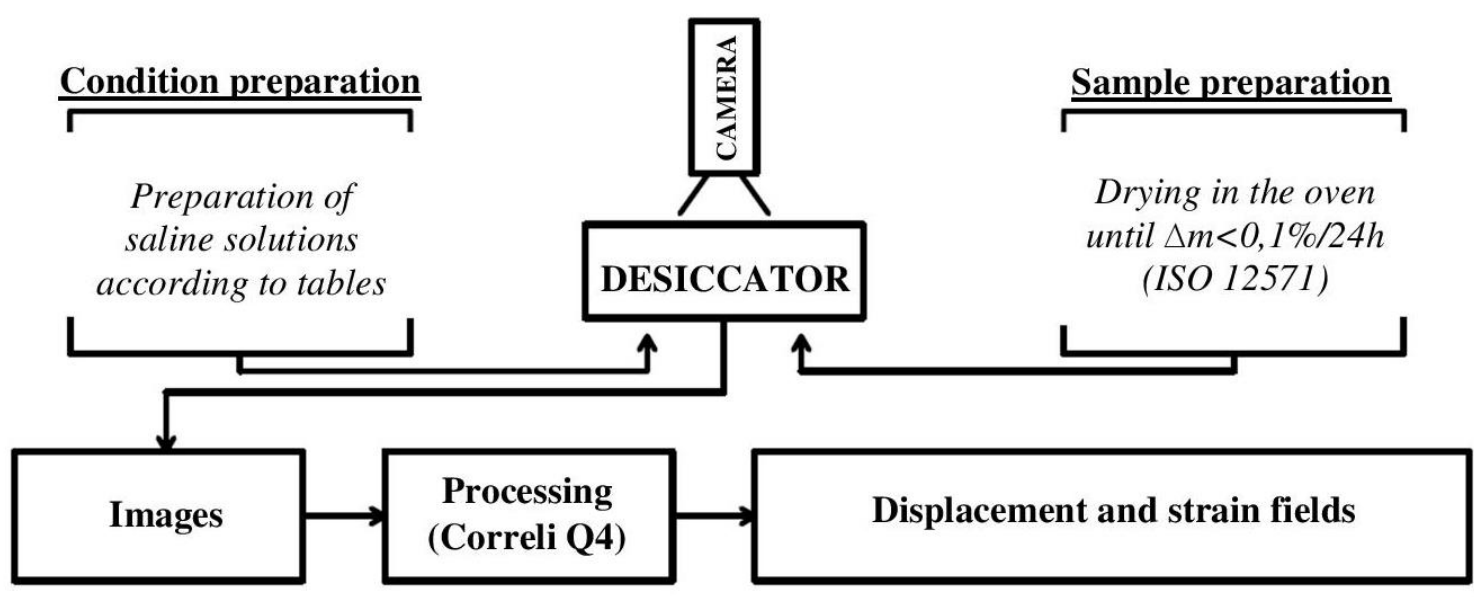

Figure 1. Protocol diagram of experimental protocol and digital image correlation tests

The experimental protocol consists mainly in preparing and keeping the samples at given temperature and humidity, controlling and following the induced deformation using optical technics and image processing coupled to variational formulation allowing the properties identification (Correli Q4 $($ ) ).

To illustrate in more realistic way, we present the photo of the experimental apparatus on figure 2. The desiccator (1) was used to unsure the experimental conditions (humidity). Pictures were taken in continuous over time, using a camera (2) and the shots' frequency was mastered by the trigger (3). The used camera is PCO-EDGE (5.5 megapixels) and has a resolution of $2560 \times 2160$ pixel2. In our study, only central pictures of 1476x1080 pixel2 have been taken to keep the central quality of the objective. Finally, a pixel size of $6.5 \times 6.5(\mu \mathrm{m})$ was obtained, on our picture size of $9.6 \times 7 \mathrm{~mm}$. Subsequently, using a computer (4), images were processed using Correli Q4 program developed in the LMT laboratory [23,24].

Two LED lamps illuminate samples in the desiccator with stable frequency, which leads to avoid the influence of utility frequency on the acquisition results. The images' acquisition frequency was adjusted in order to follow the non-constant evolution of the phenomena. The frequence was as follows: one image every two minutes the first day of the experiment, one image every 10 minutes the second day of the experiment, one picture every 20 minutes for the rest of the experiment. Later, using these images, the local displacements and strains of the material are identified using the Correli Q4 software. 


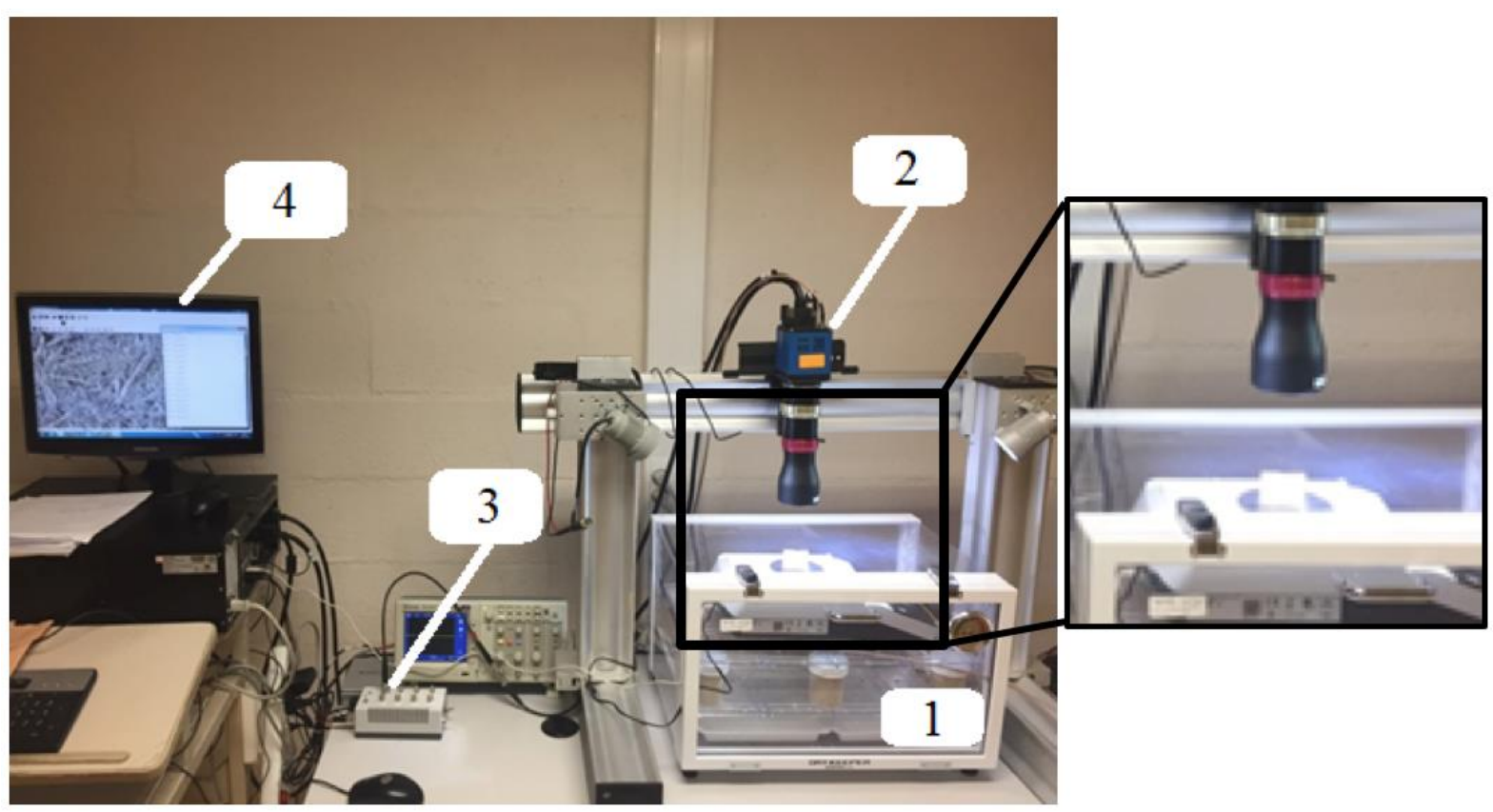

Figure 2. Photo of the experimental set-up, (1) desiccator (2) camera (3) trigger (4) computer

\subsection{Uncertainty assessment of $2 D$ digital image correlation}

The uncertainty evaluation of digital image correlation is necessary for obtaining reliable results. There are two main types of measurement errors: intrinsic and extrinsic errors. Intrinsic errors are introduced by the technique of the 2D image correlation (the software or used algorithms). There are several causes of this type of errors:

- Due to experimental solicitations, the sample receive some type of transformation. The transformation $\Phi$ is approximated by a transformation $\Phi 0$ parameterized by a set of form functions. If these form functions are not able to describe the transformation $\Phi$, the displacement measurement is tainted with errors.

- The grey level for the non-integer coordinate points (expressed in pixels) are obtained by the interpolation on the gray levels of the neighboring pixels. This process is expensive in terms of computation time but it ensures the continuous correlation coefficient. Due to this interpolation, the displacement values will be overestimated or underestimated [25].

Regarding to the extrinsic errors of the image correlation, they are related to the image acquisition and not to the correlation process. Among the sources of these errors one may note:

- Significant errors could be introduced by geometric defects of optical devices which lead to the imperfect positioning of pixel coordinates.

- The fact that two images were acquired under the same conditions but in different moments makes that they do not have identical gray levels. This intrinsic noise of the images can be a source of uncertainty. The influence of its effect could be minimized by working on images with a great depth of gray level and high-contrast textures, and secondly by choosing a size of the zone of interest large enough to reduce the noise sensitivity [26].

- Since the displacements and strains measurements are made just in the plane, the out-of plane movements of the studied sample or the bad positioning of the camera could induce some parasitic deformations.

Concerning our case, the previous last reason of the off-plan sample movement is amplified by the swelling. However, this effect does not affect the results because the used telecentric lenses take only perpendicular rays to the camera sensor. Concerning other sources of errors, before acquisitions we need to determine the reliability of the measurements. For that, we evaluate the uncertainty of obtained results. Other phenomenon that could cause 
measurement errors are variations of lighting, vibrations and a slight variation of the field's depth and sharpness. On the other hand, the accuracy of the measurements also depends on other factors such as the quality of the speckle patterns and the choice of correlation parameters (size and spacing of the zone of interest, type of interpolation, etc.). Therefore, the accuracy of the test will be given as a result of the deformations measurements between two successive images, in the equilibrium state, recorded under the test experimental conditions.

\subsection{Contrast and correlation resolution}

At the beginning, we took into consideration and minimized as much as possible all the effects that can influence the result (vibration, shadow of objects, etc.). The determination of correlation resolution is essential to receive reliable results with the smallest possible calculation uncertainty, because the size of zones of interest (ZOI) influences the noise obtained; smaller are the zone of interest, bigger is the uncertainty as there are more ZOI. Therefore, the uncertainty study was performed to determine the best conditions of the image correlation (surface treatment and contrast, correlation resolution). To evaluate the calculation uncertainty values for different correlation resolutions $(8 \times 8,16 \times 16,32 \times 32,64 \times 64$ pixels2), standard deviation values of displacement and strain fields were determined for each resolution in the case of ten correlations between successive images all taken at a thermal and water equilibrium state.

First, the study of the influence of a surface texture has been performed. The image correlation technique takes into account the gray level of the sample. Consequently, the more contrast we have in an image, the more reliable results we will get. To increase the contrast of the image, speckle patterns were used. An uncertainty was then calculated on displacement and strain fields using the image correlation axes (directions 1 and 2) for the same sample for two cases - without and with speckle patterns. The displacements and strains measurements will be explained in section 3 .

Images of the same wood sample without and with speckle patterns are presented in Fig. 3 (a) and (b), respectively. If we compare the uncertainty on displacement and strain fields for the case without speckles (Figure 4, a and c) and those with speckles (Figure 4, b and d), we note that those of the second category decrease by half the uncertainty of the correlation. At the same time, it can be seen in Figure $4 \mathrm{~b}$ that the uncertainty curve on displacements in the direction 1 is shifted from that in the direction 2 . This is related to the sensor opening frequency of the camera and presents a difference that is bearable. So thereafter for testing, speckle patterns will be used. In addition to remove glare effects and to obtain the plane surface, the sample was polished.

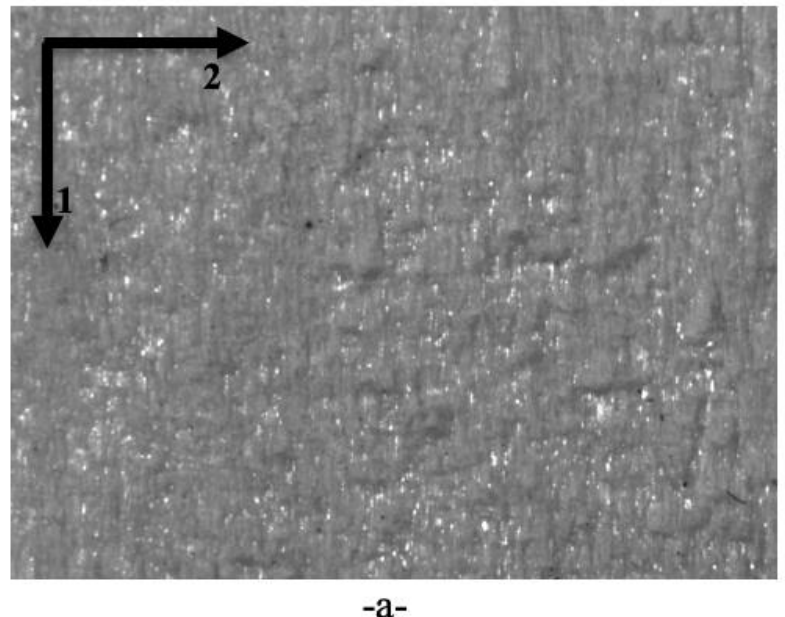

-a-

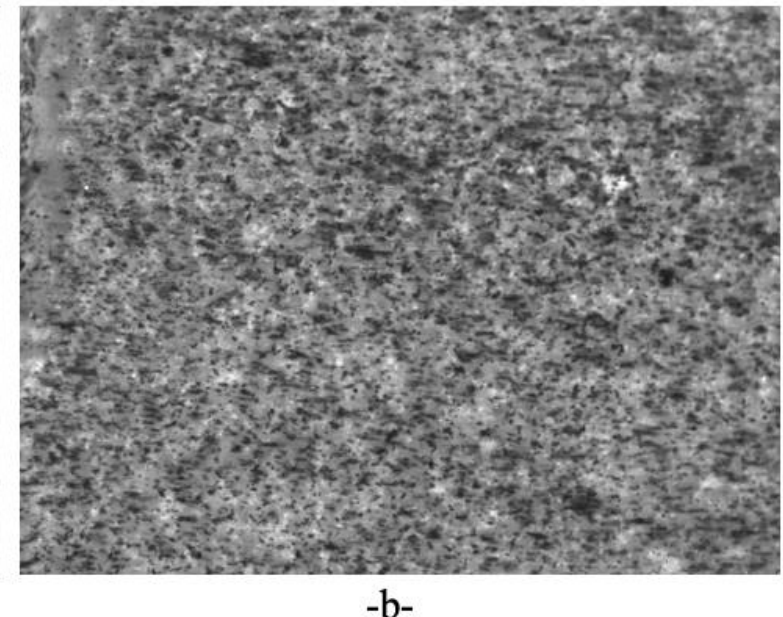

$-b-$ 
Figure 3. Images (using Keyence) of wood samples without (a) and with (b) speckle patterns at dry state (after oven drying)
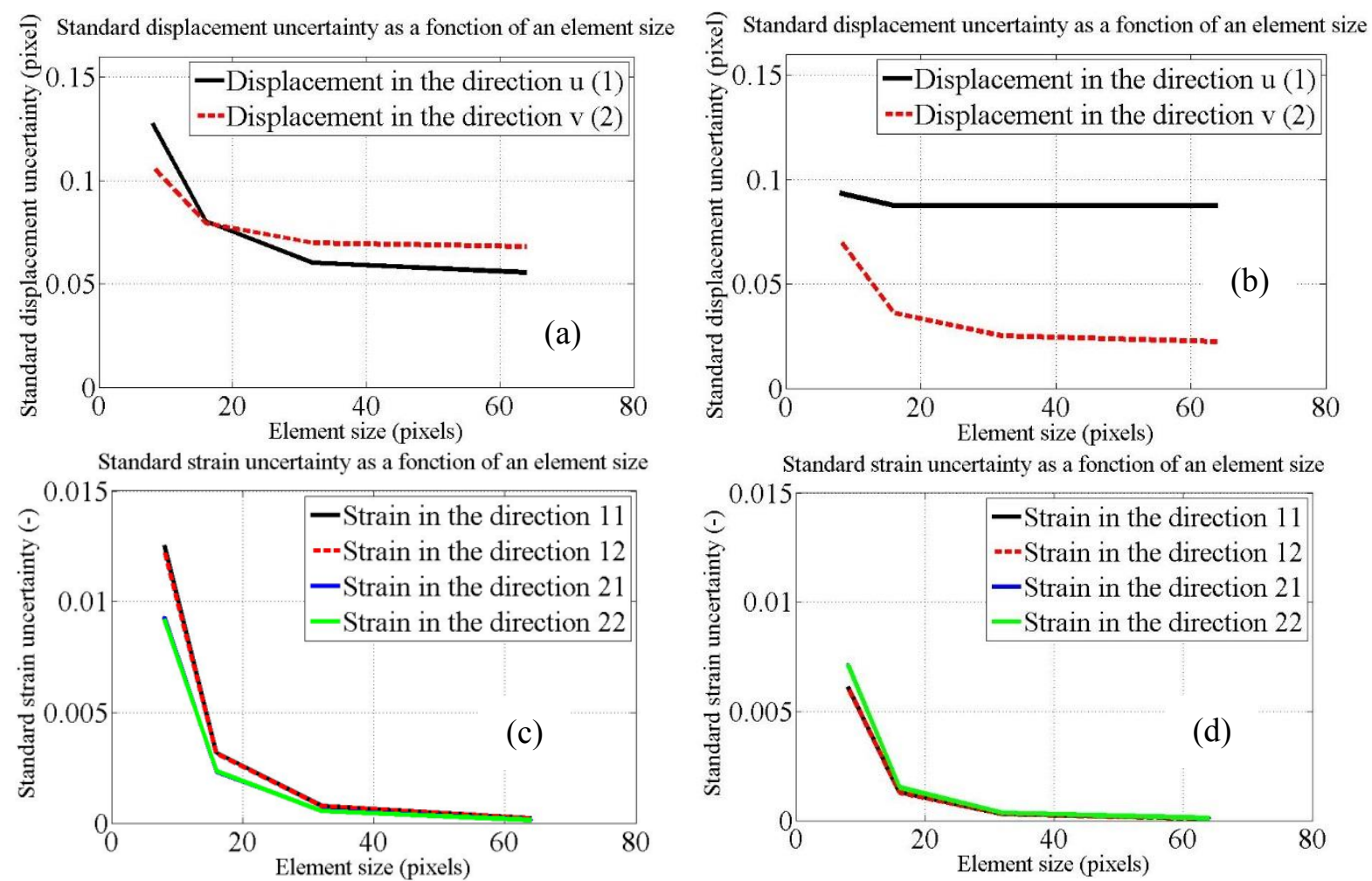

Figure 4. Curves of uncertainty evolution on displacements and strains as a function of the size of the ZOI (pixel size $=6.5 \mu \mathrm{m}$ ) for spruce samples without $(\mathrm{a}, \mathrm{c})$ and with $(\mathrm{b}, \mathrm{d})$ the speckle patterns respectively

In figure 5, the image obtained under the Keyence microscope with the earlywood and latewood (highlighted) is presented. We note the difference of the cell size in function of the type of the wood that can be noticed even visually (as a latewood represents smaller cells, it has bigger density and is darker than earlywood tissue).

The uncertainty study was done on the two wood types zones for the two chosen sample given in table 1 and illustrated on Figure 6. For each zone, as in the previous case, a study of the measurement uncertainty has been performed. So, we obtained displacements' uncertainty values in two perpendicular directions 1 and 2 (as indicated on figure 3). As for the strains' uncertainty values, we obtained the corresponding results for directions: 11, 12, 21 and 22 . Uncertainty has been determined depending on the direction. However, to obtain a single value of an overall intrinsic error to the acquisition, regardless of the samples' directions, the geometric mean was calculated using the Equation (1).

$$
G\left(x_{1}, x_{2}, \ldots, x_{n}\right)=\sqrt[n]{x_{1} \cdot x_{2} \cdot \ldots \cdot x_{n}}=\left(\prod_{i=1}^{n} x_{i}\right)^{1 / n}
$$

The results of standard displacement and strain uncertainties as a function of the ZOI size are presented in the figure 7. 


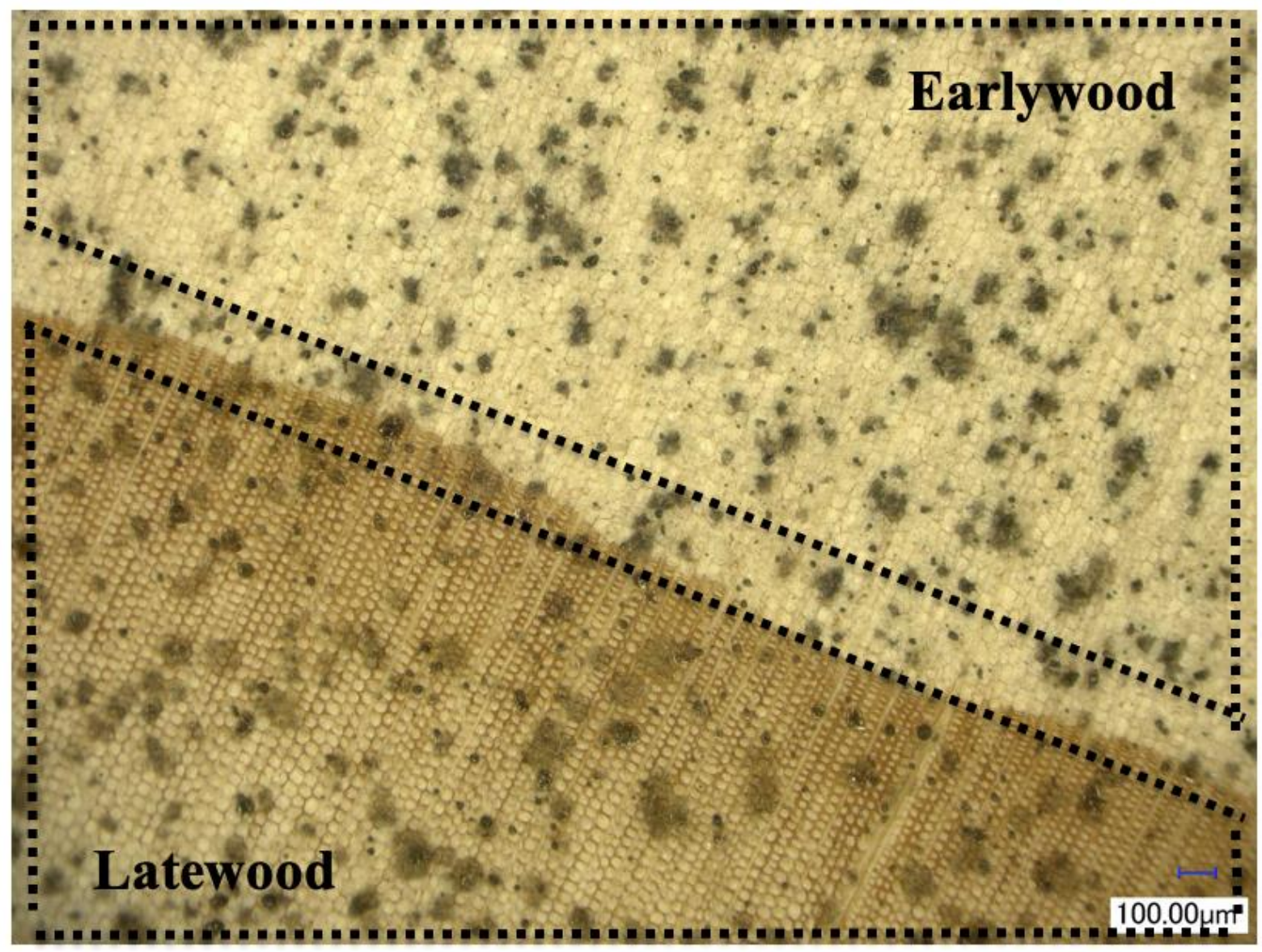

Figure 5. Image of the polished wood sample, covered with speckle patterns and highlighted as follows: earlywood and latewood (by Keyence)
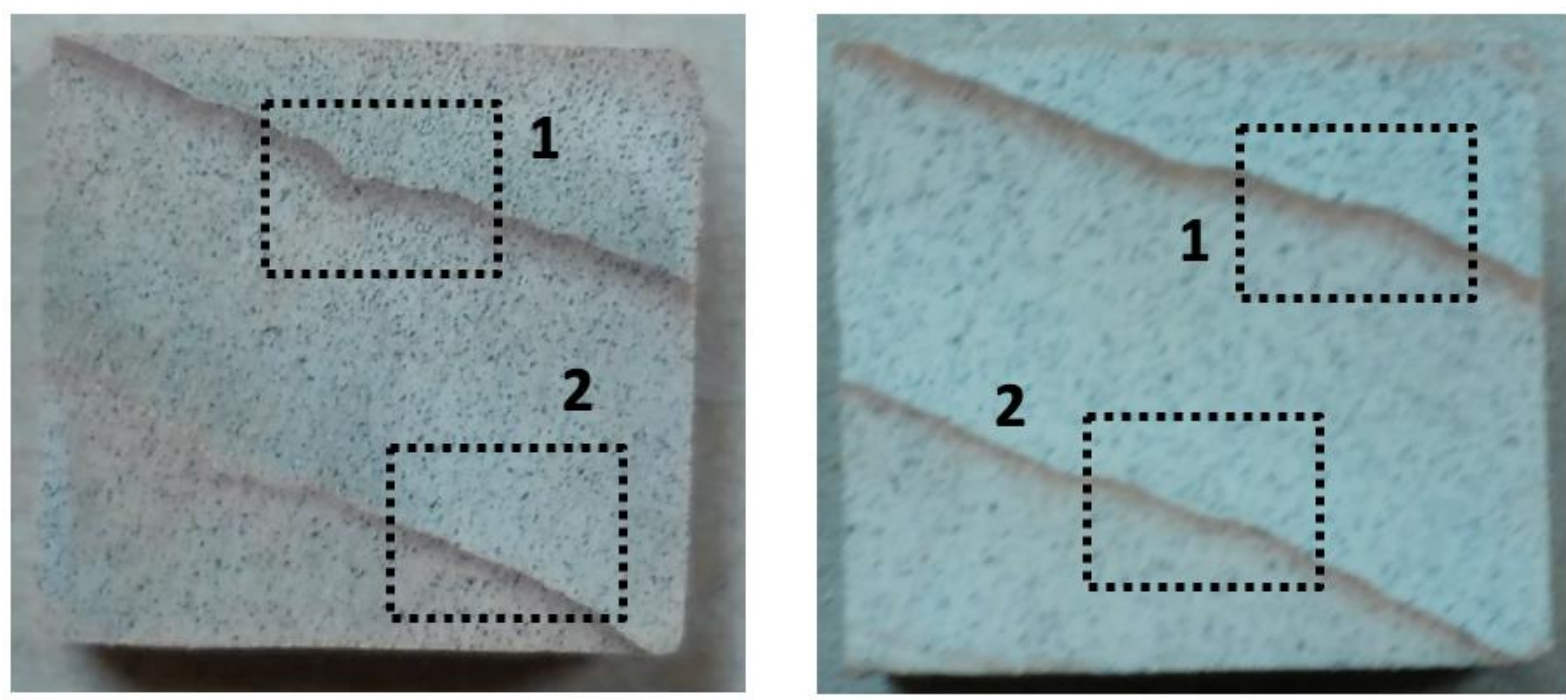

Figure 6. Photos of two samples with the highlighted and numbered zones used for uncertainty estimation

One can see that uncertainty values clearly differ specifically depending on the ZOI size. This variability depends as well on the quality of the sample its polishing and speckles treatment. Thereafter, the second zone of the first sample and the first zone for the second sample were chosen to make the digital image correlation experiment, because they represent the smallest displacement and strain uncertainties. Since we are interested in strains evaluation 
of the samples and we expect 2-6\% strain magnitude order (depending on direction and conditions), we choose the $16 \times 16$ pixel2 ZOI size which leads to a strain determination uncertainty of $0.12 \%$ and $0.09 \%$ for samples 1 and 2 respectively. The ZOI size of $8 \times 8$ pixel 2 represents an uncertainty of $0.39 \%$ and $0.54 \%$ for samples 1 and 2 respectively, that is unsuitable regarding the sought values.

The 16-pixel ZOI size with the $6.5 \mu \mathrm{m}$ pixel size (camera feature) is equivalent to a square of $104 \mu \mathrm{m}$ side. As noted before, the size of the solid wood cells is 30 to $40 \mu \mathrm{m}$, and the size the cell walls is 5 to $10 \mu \mathrm{m}$. So, this size of ZOI does not give the possibility to access strains of the cell walls. As ZOI size is equivalent to 2-2.5 cells, we expect to have strain values of different woods combined - earlywood and latewood. Then we will refer and compare results with respective values in the literature.

Concerning the swelling coefficient calculation, it has been calculated using equation 2 :

$$
\beta=\frac{\epsilon}{U}
$$

With $\epsilon-$ strain (\%) and U - water content (\%) (Rafsanjani et al., 2012).

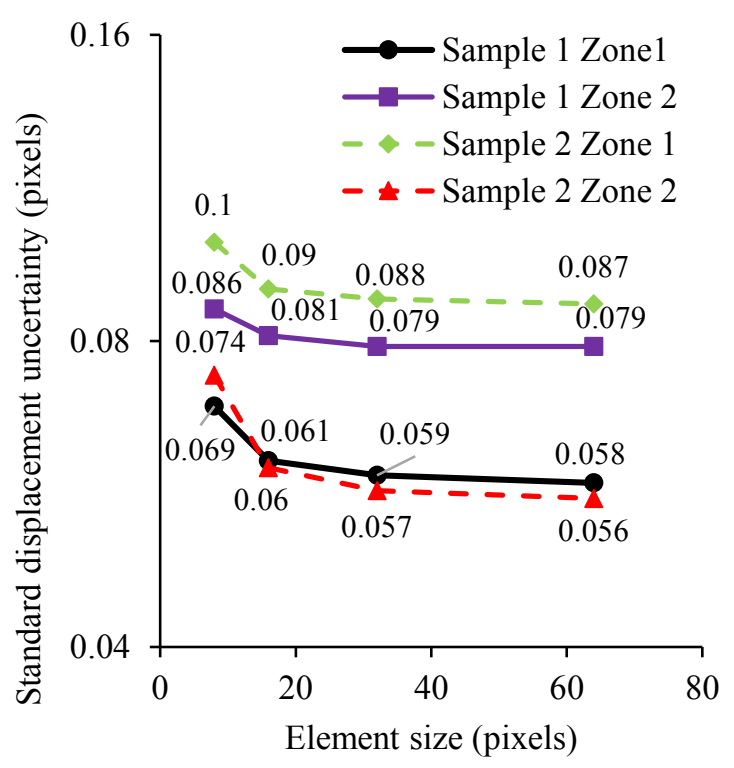

-a-

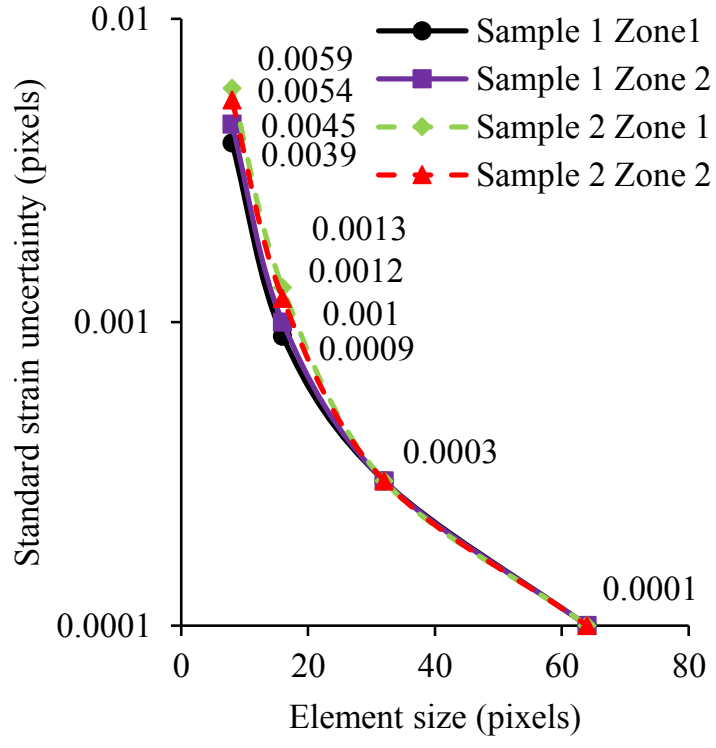

$-b-$

Figure 7. Uncertainty displacements (a) and strains (b) function of the size of the ZOI (pixel size of $6.5 \mu \mathrm{m}$ ) for two zones for each of the two wood samples

\section{Results and discussion}

In this part, various results are presented. First of all, the spruce wood behavior under water content hysteresis was evaluated by image correlation and mass tracking which provides with strain and displacement values for different directions. After that, the swelling coefficient was identified and compared for two samples for two passages of relative humidity from $75 \%$ to $84 \%$ and from $84 \%$ to $93 \%$.

\subsection{Hysteresis and mass tracking}

In this section the results of the sorption desorption isotherm are presented. The behavior of spruce wood depends on hygric state. To better characterize this phenomenon the sample 
under hygric stress was studied according to the protocol presented in section 2 at the following levels: $0,75,84,93$ and 100\%. To study the hysteresis, humidification / drying cycles have been made for sample 1. For each acquisition, the sample was weighted before and after the test, so water content values of the sample were determined at each humidity state after equilibrium. Figure 8 shows the evolution of water content as function of relative humidity for sample under sorption and desorption cycles.

Experiment was started with the humidification of sample 1 from 0 to $75 \% \mathrm{RH}$. For the image correlation two images at extreme states have been taken: the first one - the reference in a dry state and the last one (deformed) - after reaching equilibrium with the relative humidity environment of $75 \%$ (Figure 9). The ZOI size is 16x16 pixels . After making the base change we obtained displacement fields in the RR (Figure 10-a) and TT (Figure 10-b) directions and strain fields in the RR (Figure 10-c), RT (Figure 10-d), TR (Figure 10-e) and TT (Figure 10-f) directions, where $\mathrm{R}$ is a radial direction of wood, and the $\mathrm{T}$ is the tangential one. The longitudinal direction is not represented as we work in $2 \mathrm{D}$. It can be observed that the displacements and strains are anisotropic and dependent on the anatomical structure of wood. To measure strain values a virtual gauge of Correli Q4 was used in 5 different points for each type of wood. Mean measured values are shown in Table 2. As we can see, the largest strains are at the earlywood and latewood interface. This is related to the difference in swelling properties of the earlywood and latewood cells.

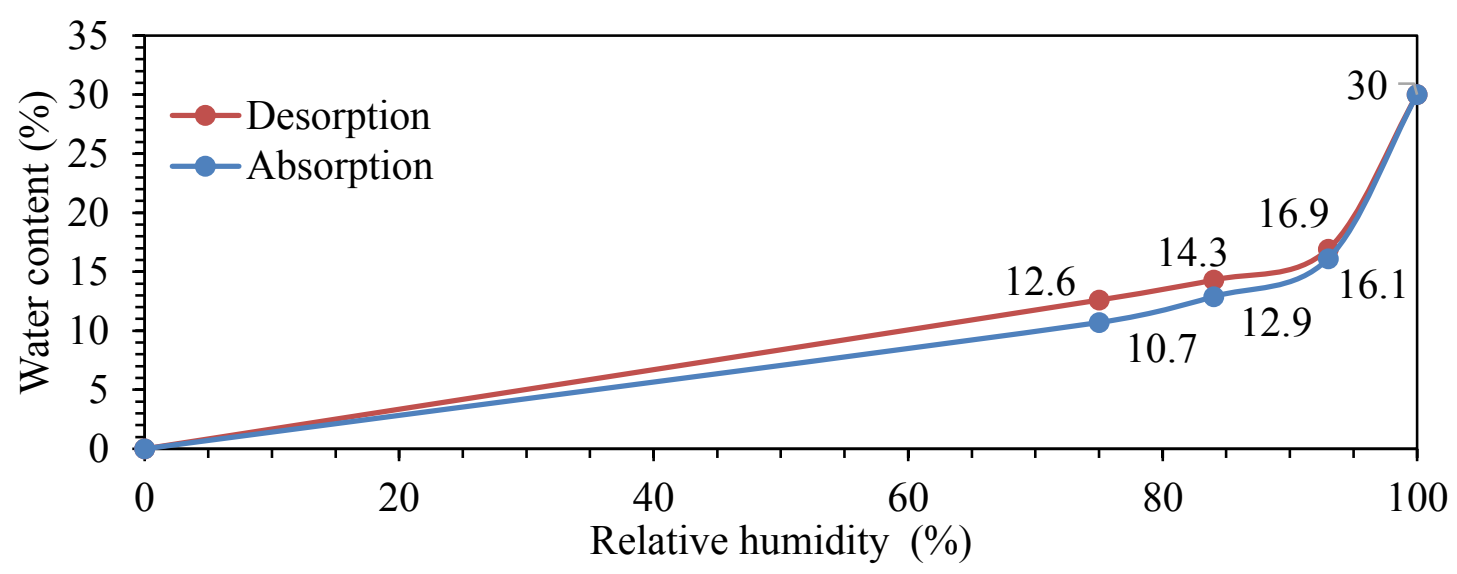

Figure 8. Sorption-desorption curve for sample 1
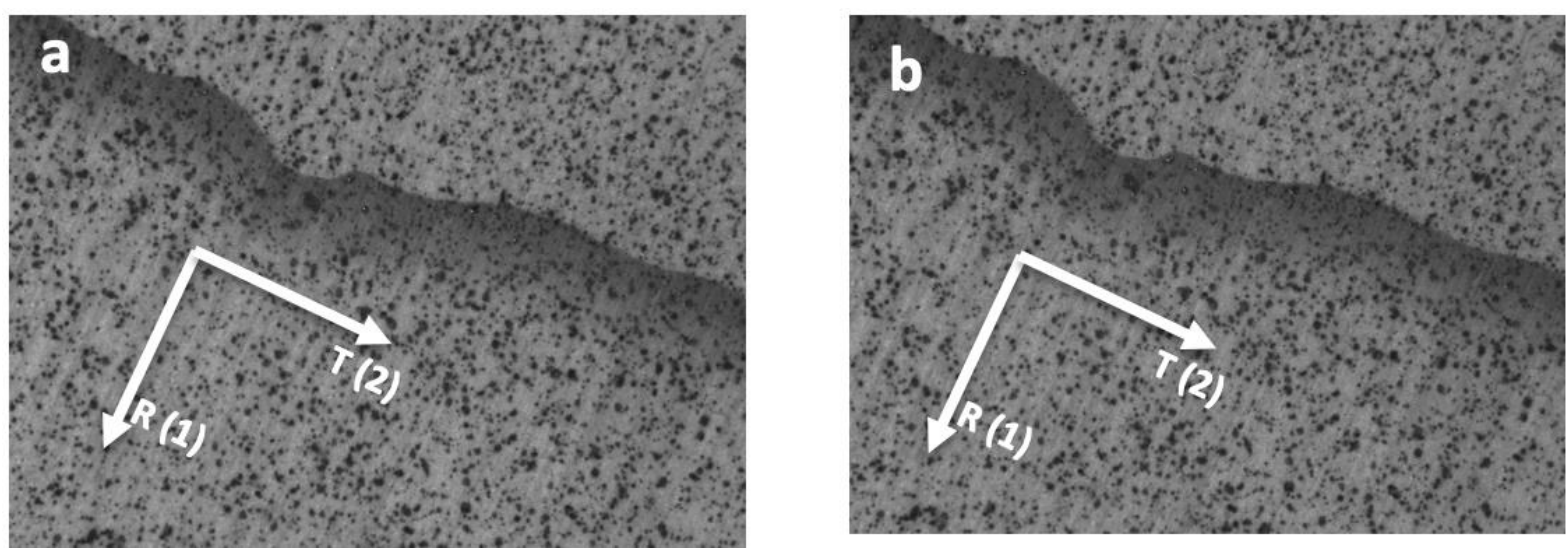

Figure 9. Reference (dry, $\left.\mathrm{T}=25^{\circ} \mathrm{C}\right)$ (a) and deformed $\left(75 \% \mathrm{RH}, \mathrm{T}=25^{\circ} \mathrm{C}\right)(\mathrm{b})$ images with the new wood structure coordinate system 

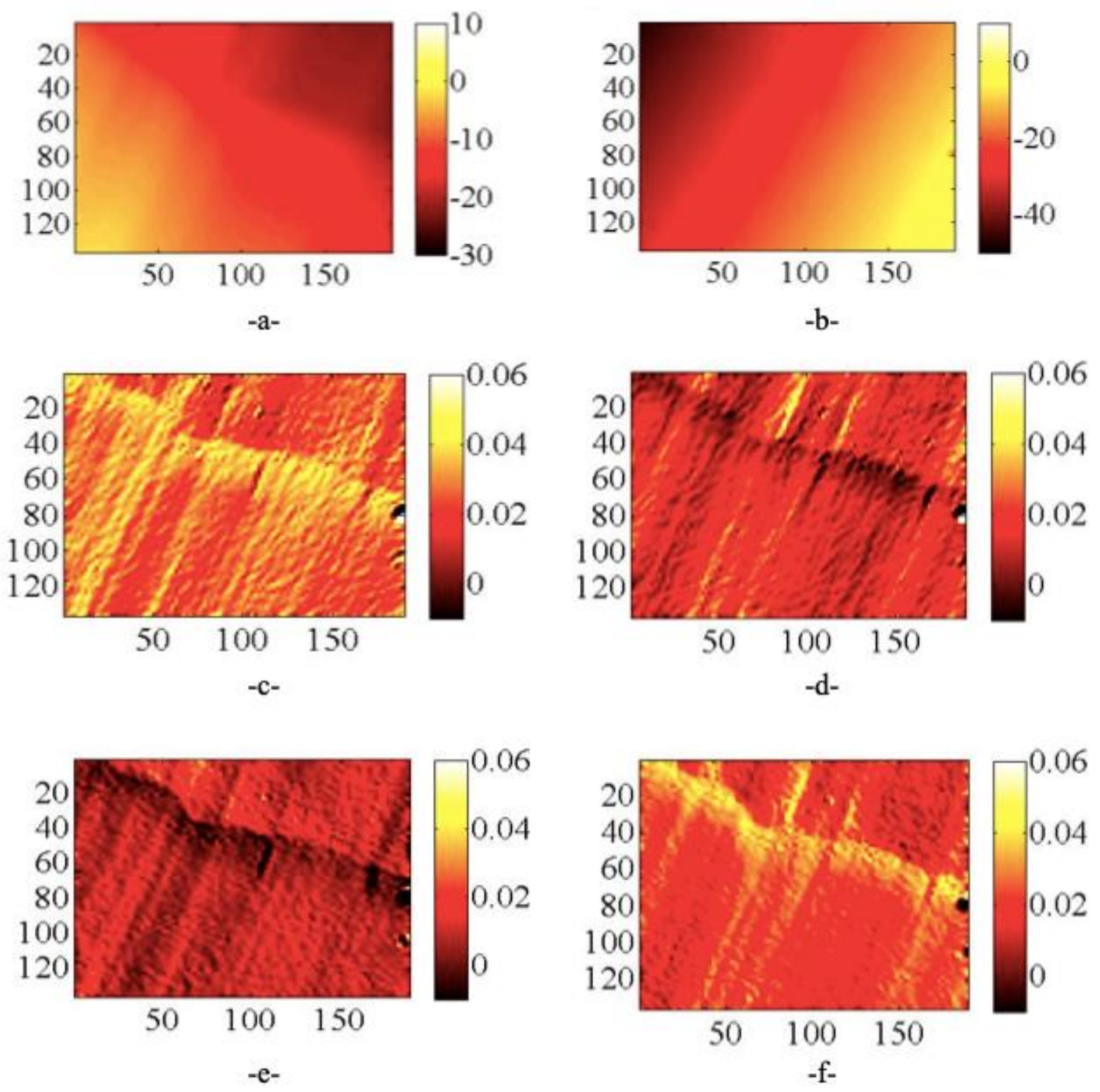

Figure 10. Displacement fields in directions RR (a) and TT (b) and the Strain fields in directions RR (c), RT (d), TR (e) and TR (f), scale axis in pixel

Table 2. Measured strains values for different wood types for the humidification stage for the humidity range from $0 \%$ to $75 \% \mathrm{RH}$

\begin{tabular}{|c|r|c|}
\hline \multirow{2}{*}{ Wood type } & \multirow{2}{*}{ Strains } & $\begin{array}{c}\text { Measured values (\%) } \\
\text { (sample 22x20x10 mm3, acquisition area } \\
\end{array}$ \\
& & $9.6 \times 7 \mathrm{~mm} 2)$ \\
\hline \multirow{2}{*}{ Earlywood } & Radial & $0.81 \pm 0.12$ \\
\cline { 2 - 3 } & Tangential & $2.34 \pm 0.12$ \\
\hline \multirow{2}{*}{ Latewood } & Radial & $3.13 \pm 0.12$ \\
\cline { 2 - 3 } & Tangential & $3.65 \pm 0.12$ \\
\hline
\end{tabular}

In order to compare obtained results we used the values of swelling coefficients determined by Rafsanjani et al. [21]. Corresponding to each direction and type of wood coefficients was multiplied by the water content variation (for example the humidification from 
0 to $75 \% \mathrm{RH}$ induced a water content increase by $10.7 \%$ ). Obtained strain values were compared with the measured ones (Table 3). Good concordance can be observed.

Table 3. Swelling coefficients for each type of wood [21], literature strain values (calculated with swelling coefficients) and measured strain values for different wood types for the transition from $0 \%$ to $75 \% \mathrm{RH}$; * (Rafsanjani et al, 2012)

\begin{tabular}{|c|c|c|c|c|c|}
\hline \multirow{2}{*}{ Wood } & Strains & $\begin{array}{c}\text { Axial swelling } \\
\text { coefficient } \beta *\end{array}$ & \multirow{2}{\Delta}{$\begin{array}{c}\Delta \text { water } \\
\text { content } \\
(\%)\end{array}$} & $\begin{array}{c}\text { Literature } \\
\text { strain values } \\
(\%)\end{array}$ & $\begin{array}{c}\text { Measured } \\
\text { strain values } \\
(\%)\end{array}$ \\
\hline \multirow{2}{*}{ Earlywood } & Radial & 0.065 & & 0.7 & $0.81 \pm 0.12$ \\
\cline { 2 - 3 } \cline { 5 - 6 } & Tangential & 0.207 & \multirow{2}{*}{$10.7 \%$} & 2.21 & $2.34 \pm 0.12$ \\
\cline { 1 - 2 } \cline { 5 - 6 } Latewood & Radial & 0.3 & 3.21 & $3.13 \pm 0.12$ \\
\cline { 2 - 3 } \cline { 5 - 6 } & Tangential & 0.347 & 3.71 & $3.65 \pm 0.12$ \\
\hline
\end{tabular}

Following the same experimental protocol, we tested all the relative humidity states for the sorption-desorption curve from 0 to $93 \%$. As was pointed out before, absorption and desorption occur for spruce wood up to a water content of $30 \%$, then the wood absorbs free water in the pores which does not affect the swelling [27]. Therefore, we take the maximum value of $30 \%$. Obtained resultants are presented as a comparison of tangential and radial strains for both types of wood (earlywood and latewood) for measured and literature values in figures 11-a and 11-b respectively. The same tendency could be noted, that both tangential and radial strain are greater for latewood than the same ones for earlywood for all passages of relative humidity. It is due to the microstructure and the character of wooden tissue - smaller size of latewood cells causes the bigger density of latewood and as a result greater strains. As the difference of size in the radial direction is larger the in tangential direction, so the difference of strains has the same trend.

At the same time, one can note that strain values are different for the same passages for different direction (humidification or drying). This phenomenon represents the hysteresis. Since the deformation is dependent of the water content evolution, the bigger is the $\Delta$ water content, the bigger is the strain. For example, tangential strains for latewood for the passage from 0 to $75 \% \mathrm{RH}$ is $3.65 \%$ for humidification and $4.41 \%$ for drying. It coincides with the curve of hysteresis as there are bigger loss of water content during drying $(12.6 \% \mathrm{RH})$ than gain during humidification $(10.7 \% \mathrm{RH})$ on the range from $0 \%$ to $75 \% \mathrm{RH}$. The same tendency was notes for all passages.

The obtained results represent a good coherence between the literature and measured values. The literature results are within the uncertainty limits of the obtained results, which can be explained by the specific anisotropic structure of wood (Figures 16,17). At the same time Rafsanjani et al. [21] has determined swelling coefficients of each type of wood for the passage from $25 \%$ to $85 \%$ of relative humidity. In our case the whole range of humidities has been studied from $0 \%$ to $100 \% \mathrm{RH}$. Represented results show the effects responding to the proposed hypothesis: the difference between wood types' shrinkage and swelling is due to the microstructure and the character of wooden tissue, the main component of cell walls. As latewood cells are smaller and thicker than early wood cells, latewood represent bigger density and as a result bigger swelling than earlywood. In addition, in tangential direction both earlywood and latewood present bigger density (wood tissue content, cell wall content) than in radial direction. In the tangential direction, the strain is about 1.5 times greater for the latewood and in the radial one - around 4 times larger for the latewood (comparing with the earlywood). The same behavior was noticed on all other images, which confirm the results obtained. 

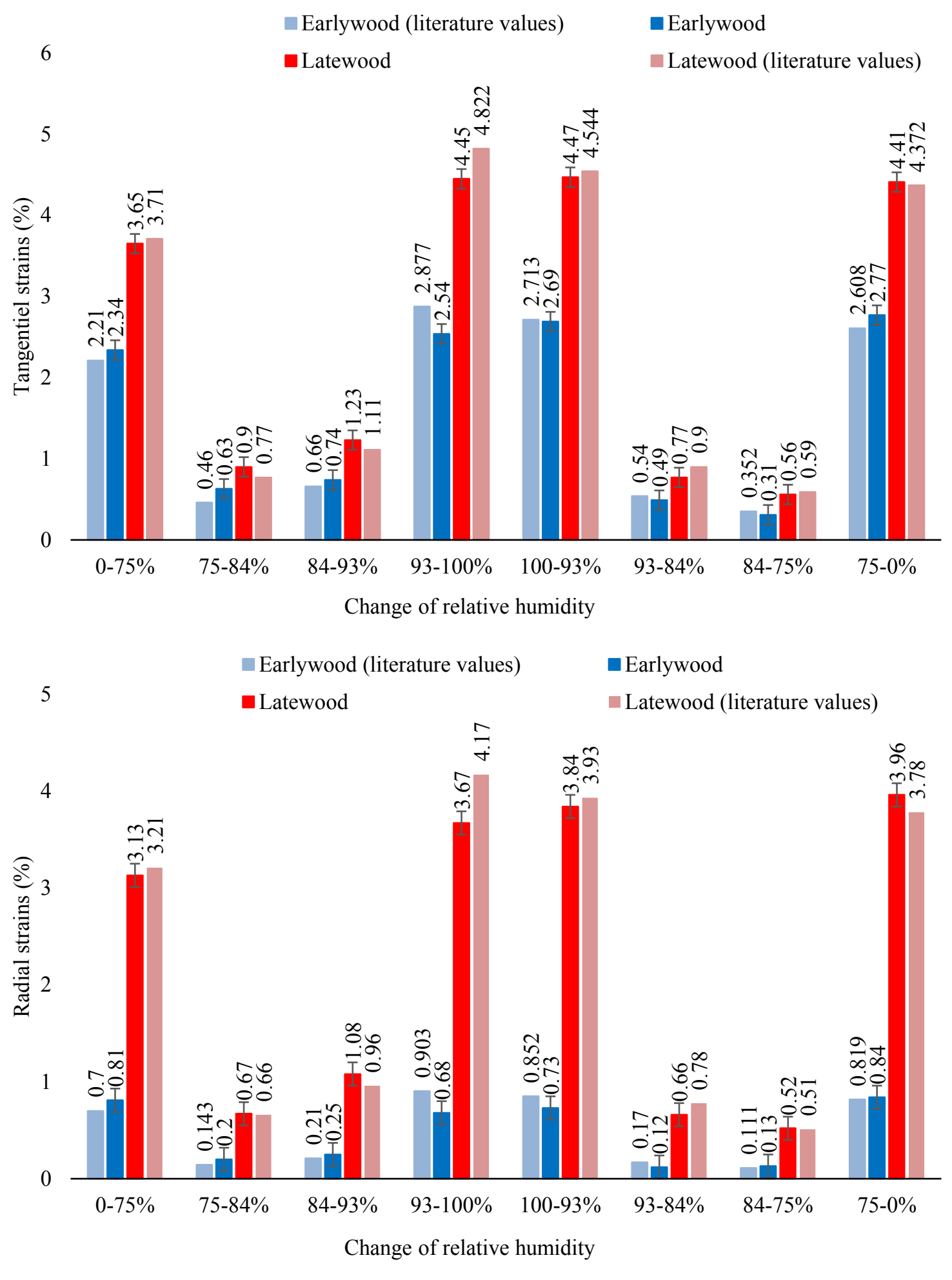

$-b-$

Figure 11. Diagram of strains tangential (a) and radial (b) for both wood types as a function of relative humidity changes $(\%)$ in comparison with the literature values obtained

by Rafsanjani et al. [21] 


\subsection{Swelling coefficient ( $\beta$ ) identification}

In order to compare the obtained results, we used the same technique for the second sample, for which we used transitions of relative humidity from $75 \%$ to $84 \%$ and from $84 \%$ to $93 \%$. In table 4 , strain values due to relative humidity change from $75 \%$ to $84 \%$ (with $\Delta$ water content $=3.15 \%$ ) and from $84 \%$ to $93 \%$ (with $\Delta$ water content $=2.91 \%$ ) for two samples are represented.

Table 4. Measured strain values for both wood types for different transitions for two samples: between $75 \%$ and saturation and between saturation and $0 \%$ of relative humidity

\begin{tabular}{|c|c|c|c|c|c|c|}
\hline \multirow{2}{*}{ :0̊ } & \multirow{2}{*}{ 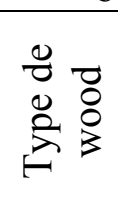 } & \multirow{2}{*}{ 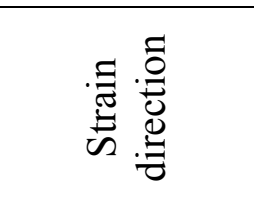 } & \multicolumn{2}{|c|}{$\Delta$ water content $(\%)$} & \multirow{2}{*}{$\begin{array}{c}\text { Sample } 1 \\
\text { Experimental } \\
\text { values }(\%)\end{array}$} & \multirow{2}{*}{$\begin{array}{c}\text { Sample } 2 \\
\text { Experimental } \\
\text { values }(\%)\end{array}$} \\
\hline & & & Sample 1 & Sample 2 & & \\
\hline \multirow{4}{*}{ 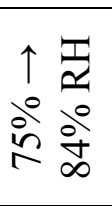 } & Early & Radial & \multirow{4}{*}{$2.2 \%$} & \multirow{4}{*}{$3.15 \%$} & $0.18 \pm 0.12$ & $0.19 \pm 0.09$ \\
\hline & wood & Tangential & & & $0.57 \pm 0.12$ & $0.6 \pm 0.09$ \\
\hline & Late & Radial & & & $0.67 \pm 0.12$ & $0.90 \pm 0.09$ \\
\hline & wood & Tangential & & & $0.9 \pm 0.12$ & $1.09 \pm 0.09$ \\
\hline \multirow{4}{*}{ 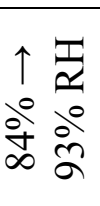 } & Early & Radial & \multirow{4}{*}{$3.2 \%$} & \multirow{4}{*}{$2.91 \%$} & $0.25 \pm 0.12$ & $0.24 \pm 0.09$ \\
\hline & wood & Tangential & & & $0.74 \pm 0.12$ & $0.62 \pm 0.09$ \\
\hline & Late & Radial & & & $1.08 \pm 0.12$ & $0.89 \pm 0.09$ \\
\hline & wood & Tangential & & & $1.23 \pm 0.12$ & $1.04 \pm 0.09$ \\
\hline
\end{tabular}

In this case, one cannot compare results obtained directly because at a specific relative humidity state, the water content is not the same for both samples. Therefore, we will compare the swelling coefficient $\beta$, which can be calculated by dividing the measured strain value (\%) by the water content $\Delta(\%)$. Comparative diagrams obtained for the passage from $75 \%$ to $84 \%$ and from $84 \%$ to $93 \%$ are shown in Figures 12-a and 12-b respectively. One can notice, there is a consistency between the obtained results (taking into consideration the uncertainty value). As previously, we note that the swelling of the earlywood is lower that one of the latewood and especially in the radial direction. At the same time, we can see that the uncertainty is high in comparison with identified swelling coefficients. So for better identification the relative humidity range must be increased. 

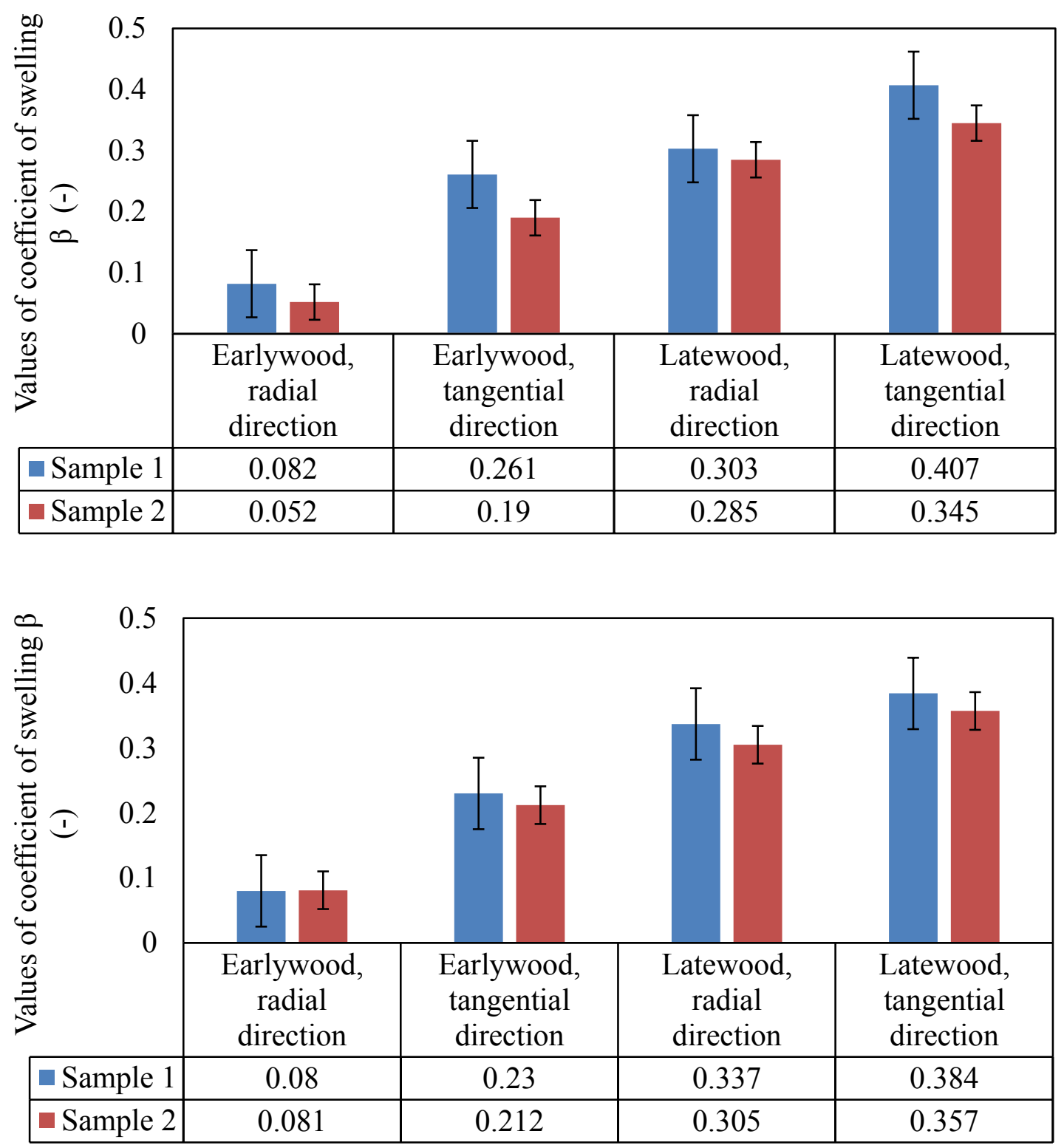

Figure 12. Diagram of swelling coefficient of a wood type and a direction (two samples) for transition from $75 \%$ to $84 \%$ (a) and from $84 \%$ to $93 \%$ (b)

\section{Conclusion}

The work reported here is part of the research themes aimed at improving knowledge on the properties of biosourced materials. At first, the literature was studied according to which we determined the targets of this study. Spruce wood was investigated in this study. The objective is to evaluate and analyze local behavior of spruce wood under hygroscopic stresses, and to link this behavior to the microstructure of the material in question. The study of the bibliography was made, which showed a lack of work on the quantitative approach to the behavior of biosourced materials under hygric stresses. The existing solutions, as 3D microtomography, demand important financial resources. That's why, to perform the tests, we have developed the experimental protocol based on the 2D digital image correlation technique adapted for biosourced materials for testing under different decoupled stresses.

The experimental study results: 
- confirmed that studied material represents a susceptibility to dimensional variations, there is the impact of the anatomical microstructure and the anisotropy of the wood on its hygromorphic behavior;

- demonstrated that the strains in tangential direction is about 1.5 times and about 4 times then radial ones for latewood and earlywood respectively. The same behavior was obtained for all tests on the range from $0 \%$ to $100 \% \mathrm{RH}$;

- allowed to identify the local swelling coefficients with rather good precision. For future tests the increase of relative humidity range is recommended due to better precision;

- showed that proposed 2D digital image correlation technic could be used for precise investigation of local behavior of different hygroscopic materials for substitution of 3D microtomography correlation;

- can subsequently be used for modeling the thermo-hygro-mechanical mesoscopic behavior of biosourced materials. These data will also help to learn about interaction problems between different types of wood;

- provide the literature and future research with promising results especially on the evolution of the microscopic morphology of biosourced materials when they are exposed to solicitations of relative humidity, which can significantly affect their macroscopic behavior.

Among the perspectives - use of this protocol for tests under thermal stresses and those coupled. 


\section{References}

[1] ADEME. Climat, Air et Energie. Chiffres clés - édition 20182018.

[2] Hervé V, Mothe F, Freyburger C, Gelhaye E, Frey-Klett P. Density mapping of decaying wood using X-ray computed tomography. International Biodeterioration \& Biodegradation 2014;86:358-63. https://doi.org/10.1016/j.ibiod.2013.10.009.

[3] El Hachem C, Abahri K, Vicente J, Bennacer R, Belarbi R. Hygromorphic characterization of softwood under high resolution X-ray tomography for hygrothermal simulation. Heat Mass Transfer 2018;54:2761-9. https://doi.org/10.1007/s00231-0182311-9.

[4] Fredriksson M. On Wood-Water Interactions in the Over-Hygroscopic Moisture Range-Mechanisms, Methods, and Influence of Wood Modification. Forests 2019;10:779. https://doi.org/10.3390/f10090779.

[5] Trechsel HR. Moisture analysis and condensation control in building envelopes. West Conshohocken, PA: ASTM; 2001.

[6] Navi P, Heger F. Comportement thermo-hydromécanique du bois: applications technologiques et dans les structures. Lausanne: Presses polytechniques et universitaires romandes; 2005.

[7] O'Leary P, Hodges PA. The relationship between full penetration uptake and swelling of different fluids. Wood Science and Technology 2001;35:217-27. https://doi.org/10.1007/s002260100096.

[8] Brunauer S, Emmett PH, Teller E. Adsorption of Gases in Multimolecular Layers. J Am Chem Soc 1938;60:309-19. https://doi.org/10.1021/ja01269a023.

[9] Hailwood AJ, Horrobin S. Absorption of water by polymers: analysis in terms of a simple model. Transactions of The Faraday Society 1946. https://doi.org/10.1039/TF946420B084.

[10] Peirce FT. A two-phase theory of the absorption of water vapour by cotton cellulose. Null 1929;20:T133-50. https://doi.org/10.1080/19447022908661486.

[11] Simpson W. Sorption Theories Applied To Wood. Wood and Fiber Science 1980;12:183-95.

[12] Olmedo I, Bourrier F, Bertrand D, Berger F, Limam A. Discrete element model of the dynamic response of fresh wood stems to impact. Engineering Structures 2016;120:1322. https://doi.org/10.1016/j.engstruct.2016.03.025.

[13] El Hachem C, Abahri K, Leclerc S, Bennacer R. NMR and XRD quantification of bound and free water interaction of spruce wood fibers. Construction and Building Materials 2020;260:120470. https://doi.org/10.1016/j.conbuildmat.2020.120470.

[14] Skaar C. Wood-Water Relations. Berlin Heidelberg: Springer-Verlag; 1988. https://doi.org/10.1007/978-3-642-73683-4.

[15] Nakato K, Kadita S. On the cause of the anisotropic shrinkage and swelling of wood. Journal of the Japanese Forestry Society 1955;37:22-5. https://doi.org/10.11519/jjfs 1953.37.1_22.

[16] Watanabe U, Norimoto M, Morooka T. Cell wall thickness and tangential Young's modulus in coniferous early wood. J Wood Sci 2000;46:109-14. https://doi.org/10.1007/BF00777356.

[17] Boutelje JB. The Relationship of Structure to Transverse Anisotropy in Wood with Reference to Shrinkage and Elasticity. Holzforschung 1962;16:33-46. https://doi.org/10.1515/hfsg.1962.16.2.33. 
[18] Derome D, Griffa M, Koebel M, Carmeliet J. Hysteretic swelling of wood at cellular scale probed by phase-contrast X-ray tomography. Journal of Structural Biology 2011;173:180-90. https://doi.org/10.1016/j.jsb.2010.08.011.

[19] El Hachem C, Abahri K, Bennacer R. Original experimental and numerical approach for prediction of the microscopic hygro-mechanical behavior of spruce wood. Construction and Building Materials 2019;203:258-66. https://doi.org/10.1016/j.conbuildmat.2019.01.107.

[20] Boutelje JB. On shrinkage and change in microscopic void volume during drying, as calculated from measurements on microtome cross sections of Swedish pine. Svensk Papperstidning 1962;65:209-15.

[21] Rafsanjani A, Derome D, Wittel FK, Carmeliet J. Computational up-scaling of anisotropic swelling and mechanical behavior of hierarchical cellular materials. Composites Science and Technology 2012;72:744-51. https://doi.org/10.1016/j.compscitech.2012.02.001.

[22] Delage P, Audiguier M, Cui Y-J, Howat MD. Microstructure of a compacted silt. Can Geotech J 1996;33:150-8. https://doi.org/10.1139/t96-030.

[23] Besnard G, Hild F, Roux S. "Finite-Element" Displacement Fields Analysis from Digital Images: Application to Portevin-Le Châtelier Bands. Exp Mech 2006;46:789803. https://doi.org/10.1007/s11340-006-9824-8.

[24] Hild F, Roux S. Comparison of Local and Global Approaches to Digital Image Correlation. Exp Mech 2012;52:1503-19. https://doi.org/10.1007/s11340-012-9603-7.

[25] Bornert M, Brémand F, Doumalin P, Dupré J-C, Fazzini M, Grédiac M, et al. Assessment of Digital Image Correlation Measurement Errors: Methodology and Results. Exp Mech 2009;49:353-70. https://doi.org/10.1007/s11340-008-9204-7.

[26] Akkaoui A. Bétons de granulats de bois : étude expérimentale et théorique des propriétés thermo-hydro-mécaniques par des approches multi-échelles. Université Paris-Est, 2014.

[27] El Hachem C, Ye P, Abahri K, Bennacer R. Fiber's hygromorphic effect on thermal conductivity of wooden fibrous insulation characterized by X-ray tomography. Construction and Building Materials 2017;150:758-65. https://doi.org/10.1016/j.conbuildmat.2017.06.013. 